This is a post-peer-review, pre-copyedit version of an article published in European Journal of Information Systems. The definitive publisher-authenticated version [European Journal of Information Systems. 11 (4) 251-266] is available online at: [http://www.palgravejournals.com/ejis/journal/v11/n4/full/3000436a.html]

\title{
THE GOLDEN CIRCLE: A WAY OF ARGUING AND ACTING ABOUT TECHNOLOGY IN THE LONDON AMBULANCE SERVICE
}

\author{
Kathy McGrath \\ Department of IS and Computing, Brunel University, UK \\ Email: Kathy.McGrath@brunel.ac.uk
}

\begin{abstract}
This paper analyses the way in which the London Ambulance Service recovered from the events of October 1992, when it implemented a computer-aided despatch system (LASCAD) that remained in service for less than two weeks. It examines the enactment of a programme of long-term organizational change, focusing on the implementation of an alternative computer system in 1996. The analysis in this paper is informed by actor-network theory, both by an early statement of this approach developed by Callon in the sociology of translation, and also by concepts and ideas from Latour's more recent restatement of his own position. The paper examines how alternative interests emerged and were stabilized over time, in a way of arguing and acting among key players in the change programme, christened the Golden Circle. The story traces four years in the history of the London Ambulance Service, from the aftermath of October 1992 through the birth of the Golden Circle to the achievement of National Health Service (NHS) trust status. LASCAD was the beginning of the story, this is the middle, an end lies in the future, when the remaining elements of the change programme are enacted beyond the Golden Circle.
\end{abstract}

\section{INTRODUCTION}

The United Kingdom London Ambulance Service (LAS) is one of the largest ambulance services in the world. It provides an accident and emergency service for London's 14 district health authorities, covers a geographical area of over 600 square miles and services a resident population of nearly 7 million. In October 1992 the LAS attempted to introduce a computeraided despatch system, LASCAD, to handle the command and control functions of the service automatically. The story of the events leading to the collapse of LASCAD has been told many times and in many ways, but what has received much less attention from academics and media alike is what has happened at the LAS since then. Between 1992 and 1996, the LAS was the subject of two major public inquiries following the failure of its computer system and the death of Nasima Begum. It attended a House of Commons Select Committee inquiry that investigated the performance of the service, and experienced various formal and informal evaluations by health authorities, Government ministers, and the media. The outcomes of these evaluations have been that the LAS was awarded National Health Service (NHS) trust status in 1996 and received a British Computer Society award for its control room and computer system in 1997 (London Ambulance Service web site, 2002; Times, 1997). 
This paper is an account of one part of the recovery of the LAS from the events of 1992, through a process of long-term, and ongoing, organizational change. It focuses on the implementation of an alternative computer system, Call Taking (CTAK), in 1996. A key aspect of this period of organizational change at the LAS, and an aspect that is analysed in some detail in this paper, is the concept of the Golden Circle. This concept describes a method of association among actors in the change programme that, to varying degrees during the analysis, emerges as exclusive and inclusive, mysterious and rational, fabricated and real. Nevertheless, at each stage it is clear that the Golden Circle helped to create a space for movement at the LAS, in which a specific information technology (IT) implementation took place in 1996. This research does not seek to explain LASCAD as exceptional failure nor CTAK as exceptional success, since such dichotomous reasoning is thought to present too narrow a view. Rather, the argument is that organizational change mixes up success and failure, and other such dichotomies, in a very messy way, so that how we think and write about it should respect these entanglements instead of trying to unravel them. This work aims to do that by drawing on actor-network theory, whilst recognizing that its major proponents have been ambivalent over the years about how they understand such intertwining.

Following this introductory section, this paper proceeds as follows. First, I explain the research approach adopted in this work, followed by a narrative description of the case material. Then, I present an analysis of organizational change at the LAS using an established vocabulary of actor-network theory - the sociology of translation (Callon, 1986; Latour, 1987). I reexamine that account, drawing on ideas from Latour's (1999a, 1999b) recent work, in which he rejects distinctions such as power and knowledge, even in the dialectical relationship that informs earlier statements of actor-network theory. Finally, I draw conclusions from this study.

\section{RESEARCH APPROACH}

Accounts of LASCAD (for example, Page et al, 1993; Financial Times, 1993; Beynon-Davies, 1995; Hougham, 1996; Wastell and Newman, 1996; Introna, 1997) present it, to varying degrees, as a project in which the interests of staff were poorly addressed by management. Explanations of managerial and staff action necessarily differ according to the model of human behaviour adopted by researchers. These accounts also refer to broader social structures prevailing at the time, although again they vary in the extent to which they examine how these social structures influenced action locally. These two elements - the nature of human agency and the way social structures influence action - are key to explaining not only why LASCAD collapsed, but also why CTAK was adopted. Hence they are a central concern of this research. Nevertheless, there are few recent debates in the social sciences that have attracted both the attention and the acrimony that have surrounded the agency-structure debate, whether argued in terms of subject-object, local-global, social-technical, power-knowledge, human-nonhuman or any other of a number of possible distinctions. This research explores the view that which distinctions we accept, and how we understand the relationship between the two elements dichotomy, dialectic or entanglement - can affect significantly the insights we gain from our work.

\section{Actor-network theory: the key debates}

Actor-network theory (Callon, 1986, 1991; Latour, 1987, 1996, 1999b) has found itself at the centre of these controversies, despite Latour's claims to have overcome them (Latour, 1991), to 
have bypassed them (Latour, 1999b), and never to have wanted involvement in them at all (Latour, 1999a). In the first case, he argues that '[s]ociety and technology are not two ontologically distinct entities but more like phases of the same essential action' (Latour, 1991, p. 129). This position suggests an attempt at resolving or overcoming the agency-structure debate, despite more recent claims (Latour, 1999a) that the original idea was to ignore or bypass it. Latour (1999b) argues that bypass rather than resolution is appropriate, since expressions like power/knowledge (Foucault, 1980a) and, by implication, structuration (Giddens, 1979, 1984), are modernist settlements, which attempt to replace a dichotomy with a dialectic in the interests of the major players, but with no concern for the audience.

As a collection of powerful tools and ideas, in which the social and technical worlds are considered to be so entangled as to define one another, actor-network theory adopts an analytical position of symmetry between humans and non-humans - a position that is at the heart of Latour's claims. This position has been the subject of controversy, with critics finding it intellectually and morally problematic to make no distinction between human action and the behaviour of things (Collins and Yearley, 1992). In other variants of this argument, actornetwork analyses are criticized for adopting a localized focus (Knights and Murray, 1994; Harbers, 1995; Reed, 1997) and an amoral stance (Winner, 1993; Knights and Murray, 1994). In this way, the approach is seen to subscribe to a flat ontology, neglecting the enduring nature of institutions as a condition for network formation as well as a consequence of it. By ignoring institutional sources of power and inequality, critics argue that actor-network theory has little to say about the systematic exclusion that prevents some social groups from having a voice in technology innovation. In such challenges, arguments based on dichotomies are at the heart of the criticism.

Proponents of actor-network theory have responded to these criticisms in debates that have been quite vitriolic. On the symmetry issue, actor-network scholars have argued that they accept the divisions and distinctions, but only when they are 'understood as effects or outcomes' (Law, 1999, p. 3, emphasis in the original), and that they refuse to consider the distinctions a priori (Callon and Latour, 1992). In the local-global debate, as in the related exchange on society-technology, actor-network scholars have been ambivalent about their position. At one time, they seemed to accept such distinctions, and argued that actor-network theory resolves or overcomes them (Callon, 1991; Latour, 1991; Law and Callon, 1992), only to argue later that such distinctions are irrelevant (Latour, 1999b). Finally, Law (1991) has argued that, although actor-network theory did not set out to have a moral agenda, it could adopt one, if researchers choose 'to think not only about heroes but also of victims and the differences between their fates' (p. 15). Nevertheless, some repair work (ibid.), including the introduction of new concepts within actor-network theory (Latour, 1999b) and the use of complementary concepts from other schools of thought, has been necessary to make this move (Walsham, 1997; Knights et al, 1997; Hull, 1999).

Some observers have commented on these debates, with a view to clarifying key arguments for the audience (for example, Walsham, 1997). Nevertheless, actor-network theory 'is not a stable body of knowledge that can be drawn on by researchers in an unproblematic way, since its developers themselves have frequently revised or extended elements of it' (Walsham, 2001, p. 46). Such critical reflection is very healthy, but in rejecting the dichotomies and dialectics with which we have become familiar, Latour's (1999b) nonmodern way of arguing requires some conceptual reorientation on the part of researchers. Challenged by his claims that discourses informed by concepts of power (Callicles), reason (Socrates), or a Foucauldian 
settlement between the two, are elitist, with no concern for a broader community, I felt a need to put these arguments to the test. This paper is the outcome, but rather than examining a Platonic dialogue, it draws on recent case material, with a contribution to practice as well as research in mind.

\section{Theoretical basis of the study}

My research approach has been informed as follows. First, I present an account of organizational change at the LAS that draws on the sociology of translation (Callon, 1986), an established collection of concepts within actor-network theory, which 'owe more than a little to the writing of Foucault' (Law, 1986, p. 18). In this version of actor-network theory, power exercised in discourse is a key concern. Then I reexamine my account, drawing on ideas from Latour's (1999a, 1999b) recent work, in which he aims to eschew distinctions such as power and knowledge, politics and morality, claiming that these are modernist arguments based on an irrelevant subject-object dichotomy. In the discussion that takes place, I find little support for Latour's charges of elitism and amorality in a Foucauldian informed analysis. Nevertheless, as I developed the argument I translated some concepts and ideas, and ended up at a place in which some interesting implications for research and practice emerged.

The concepts and ideas that inform this research are outlined as they are adopted. However, since the sociology of translation (Callon, 1986) informs a significant part of the analysis, some further description is provided here. The sociology of translation addresses how key players interact to build heterogeneous networks of human and non-human actors, forming alliances and mobilizing resources, as they strive to convert an idea into reality. The outcome of these interactions is a particular accomplishment, arrived at through four moments of translation. These four moments involve interaction to define a problem, to which the idea is a proposed solution (problematization), to arouse interest in the problem (interessement), to consolidate alliances around a negotiated solution (enrolment), and then to mobilize allies, or their representatives, for implementation (mobilization). Translation is achieved by displacements that require discourse and the exercise of power. If successful, it directs actors towards the view that the proposed solution is the only way to solve the problem. If unsuccessful, it diverts actors away from such an obligatory passage point.

\section{Research method}

This research project started in April 1998 following a presentation by the IT director of the LAS to the Project Management Specialist Group of the British Computer Society (BCS). Initially, I undertook a short study, comprising five unstructured interviews with the IT director and two managers of operations, and an afternoon of observation in the LAS control room. This work addressed the technological changes that had taken place at the LAS following the collapse of the LASCAD system. In February 2000, I began a further, longitudinal study to follow through on information systems developments and associated organizational changes that were taking place at the LAS at that time, and to relate these developments to past projects - including the LASCAD and CTAK projects - and to future opportunities. So further fieldwork relating to the events described in this paper took place over a 12-month period between February 2000 and February 2001. Overall, the fieldwork comprised the following primary elements:

- 43 unstructured and semi-structured interviews of 1 to 2.5 hours duration 
- 9 periods of observation in the LAS control room (c. 50 hours)

- Observation of 31 project meetings (over 40 hours) and 6 staff training sessions (c. 25 hours)

- 3 periods observing ambulance crews as they attend emergency calls (c. 25 hours).

In general, I used an interviewing approach with staff who support front line operations, but who do not usually work either in the control room or at emergency scenes, for example, board directors and senior managers, members of the staff training unit, IT specialists, and quality assurance advisors. I spoke with front line staff as they did their work, and as circumstances permitted these conversations. Interviews were recorded and transcribed later, whereas notes were taken during meetings and periods of observation. On most visits to LAS headquarters in London, I spent some time in an office occupied by three managers whose work supports control room operations, where I participated in conversations and ad hoc meetings that arose as these managers went about their work.

I drew upon various internal documentation sources, including meeting minutes, procedure manuals, project plans, corporate and technology strategies, project evaluation reports and staff surveys. Copies of service plans, annual reports, various internal communication videos, newspaper articles and television programmes about the LAS were available from its Press and Public Affairs office. The LAS has "official" and "unofficial" web sites. The latter contains several pages on humour, an important feature of LAS life and a way of dealing with the requirements of the job. I also drew upon the public inquiry reports into the collapse of the LASCAD system and the death of Nasima Begum (Page et al, 1993; Wells, 1995), and the reports of the House of Commons Select Committee on Health $(1995,1996)$ into the performance of the LAS.

Although some of these data relate to periods of organizational change at the LAS that are not addressed in detail in this paper, my conclusions from analysing them have contributed to the account presented here. That account adopts a 'broadly interpretive' stance (Walsham, 1993), reflecting my efforts during data analysis to identify multiple actors' interpretations of a specific four-year period of information systems implementation and related organizational change at the LAS. The account is reconstructed from public inquiry reports and peoples' memories, and further informed by my observations of the CTAK system in operation during my fieldwork efforts. The analysis focuses on the discourses of participants in the change programme, examining the statements that were articulated, those that were accepted, and the practices in which such acceptance took place. Overall, my aim was to form a view of what constituted the basis of truth for this community (Foucault, 1980b) during the period in question.

\section{THE CASE STUDY NARRATIVE}

This section presents the case study narrative. It traces the main events and initiatives that took place from the collapse of LASCAD (October 1992) through to a review by the House of Commons Select Committee on Health (December 1996) into the early performance of the LAS as a NHS trust. The base narrative is derived from the second report of the House of Commons Select Committee on Health (1995), and is supplemented with material from the research project described above. This description of technological, organizational and environmental developments constitutes the narrative to be analysed (Pettigrew, 1987, 1990) in the next section. Whilst recognizing that these developments were interrelated, limitations 
on the length of this paper permit a focus on technological changes only, so broader developments are referenced selectively, where they are considered key to understanding the technological changes examined.

\section{The aftermath of LASCAD}

Following the withdrawal of the LASCAD system, a public inquiry into the events leading to its collapse was ordered by South West Thames regional health authority. The Page inquiry report, published in February 1993, argued for a programme of investment in the LAS and a slower pace of change. Acknowledging the need for service improvements, it recommended the development of a computer-aided despatch (CAD) system that should have 'total ownership by management and staff, both within CAC [Central Ambulance Control] and the ambulance crews' (Page et al, 1993, pg. 8). A CAD system is a computerized system to handle the command and control functions of an emergency service automatically. Such a system would address most or all of the following functions to varying degrees of automation: i) call taking and gazetteer; ii) tracking of vehicles; iii) allocation and mobilization of resources to incidents; iv) ambulance resource management; and v) provision of management information.

In the months following publication of the Page report, the LAS board was abolished, the regional health authority assumed direct responsibility for the LAS and a new top management team was recruited (Wells, 1995). The revised management arrangements became fully effective in April 1994. Initially, the new senior management team focused on improvements to the organizational and technical infrastructures of the LAS (LAS, 1993, 1994a, 1994b). The regional health authority made an additional £14.8 million funding available to enable this strategy, conditional on improved performance against ORCON (Operational Research Consultancy) standards. Particular targets of responding to $80 \%$ of emergency calls within 14 minutes by September 1994, rising to 85\% by March 1995, were written into the corporate plan (LAS, 1994a). ORCON standards are nationally recognized standards of performance for UK ambulance services, which, prior to a Government sponsored review (Chapman, 1996), required that:

i) $50 \%$ of ambulances should reach patients within 8 minutes, and

ii) $95 \%$ of ambulances should reach patients either within 14 minutes, in urban areas, or within 19 minutes, in rural areas.

While the LAS was being taken back under the direct control of South Thames regional health authority, other ambulance services were applying for independence. These services were responding to a reorganization of the UK National Health Service (NHS) into a system of self-governing trusts, in which ambulance services, hospitals and community units negotiate their contractual responsibilities with regional health authorities in purchaser/provider relationships within an internal market. By April 1994, the majority of ambulance services had achieved NHS trust status. A crucial measure of the suitability of applicants for trust status is quality of service. In the case of an ambulance service, performance against ORCON standards, facilitated as appropriate by a CAD system, is a key concern (LAS, 1998a).

\section{The death of Nasima Begum}


In June 1994 the media spotlight fell again upon the LAS. Against a backdrop of the declared intention of a House of Commons Select Committee to conduct an autumn inquiry into the performance of the LAS, Nasima Begum, an eleven year old schoolgirl, died of complications from an existing kidney condition, after a 53-minute wait for an ambulance. In October 1994, the Secretary of State announced a public inquiry into this event, headed by William Wells, chairman of South Thames regional health authority. This inquiry was to run alongside the Select Committee inquiry into the future of the LAS. The results of the Wells inquiry were published first in January 1995. Whilst acknowledging an unusually high demand on 19 June 1994, Wells found 'continuing management weakness ... inappropriate staff distribution and shift changeover times and virtually a complete lack of modern technology' (report foreword). A number of recommendations were made to address these weaknesses and additional funding was agreed to enable them. The review team expressed its commitment to taking the LAS 'to a financial position where it can secure a significant improvement in performance standards and become a viable applicant for NHS trust status' (Wells, 1995, pg. 27).

Following publication of the Wells report, work on its recommendations began at the LAS. In the control room, manual operations continued during 1995, but some restructuring took place to relieve issues with ambulance allocation (LAS, 1995). Further work was done on creating a sound IT infrastructure, including building a new ambulance control room (LAS, 1998a). Work began in April 1995 on development of a call taking system. This development addressed the first of the five elements of a full CAD system referred to earlier. In effect, the aim was to replace the existing manual system of recording call details on slips of paper, and using human runners to transport the slips from the call takers to the ambulance allocators, with online data entry, and related enquiry and printing facilities. An online gazetteer was included, to replace the manual method of using a map book to determine a grid reference for the ambulance allocator.

Criticism of the LAS re-emerged in June 1995 with publication of the findings of the House of Commons Select Committee on Health (1995). Whilst endorsing Wells' recommendation that the LAS seek trust status, the Committee was concerned that 'it may not be practicable to achieve this by April 1996' (pg. lxvi). It claimed that the 'recent history of the LAS has provided an object lesson in how not to manage a public service' (pg. xxi). Findings of specific interest to the technological change emphasis in this paper include the Select Committee's comments on information systems developments at the LAS. On the issue of procuring a new computer system, the Select Committee urged the LAS to 'consider very seriously the possibility of purchasing an "off the shelf" CAD system' (pg. 1). Whilst critical of the proposed five-year timeframe to introduce a new computer system, they gave their support to 'the efforts that are now being made to improve the technical infrastructure of the LAS' (pg. xlviii).

\section{The award of NHS trust status}

Work on the bespoke development of a call taking system continued during 1995. The technological change enacted in this period took place in a discrete and self-supporting area that was analysed and dealt with in isolation from other influences. This approach, christened the Golden Circle, is discussed in the next section. Although external bodies were not allowed to interfere with the nature or manner of delivery of the change, contact was maintained with the regional health authority via weekly progress meetings with the 
chairman of the region (LAS, 1998a). The new system was due for implementation by September 1995 (Wells, 1995), to coincide with the LAS application for NHS trust status. In the event, system implementation took place during January and February 1996 (LAS, 1998a). At the same time, the decision to award trust status to the LAS was announced. Thus the LAS became an NHS trust on 1 April 1996 and has continued to operate in that way since.

Following implementation of the call taking system, performance against ORCON standards rose progressively. By the last quarter of 1996, performance against the 8-minute standard had risen to $36 \%$ from an average of $16 \%$ during 1995, while performance against the 14minute standard had risen to $91 \%$ from an average of $74 \%$ during 1995 (House of Commons Select Committee on Health, 1996). The LAS entered its new control room and call taking system into the 1997 British Computer Society awards and gained the Information Systems Management excellence award on 14 May (Times, 1997). The introduction of a call taking system in 1996 was part of a continuing programme of organizational change at the LAS. Significant challenges remain, which are discussed in a postscript immediately preceding the conclusions from this study. These challenges include incorporating the outstanding elements of a full CAD system, outlined earlier.

\section{ANALYSING THE NARRATIVE}

This section analyses the preceding narrative using the sociology of translation. Problematization examines how the regional health authority, acting for the NHS and ultimately the UK Government, defined an obligatory passage point (OPP) in NHS trust status for the LAS. A key actor in this initiative was the chairman of the regional health authority, who was able to draw on several sources of power to translate actors towards this OPP. This action involved building a network of interests around his proposed solution (interessement), in a negotiated process of consolidating alliances with other actors (enrolment). By focusing in this paper on the technological developments required for the LAS to achieve NHS trust status, the IT director emerges as a key actor in the local context. The actions he took during interessement, enrolment and mobilization of support for these developments are also discussed. Thus this analysis examines how conflicting interests emerged and were stabilized over time through the use of discourse and power within and outside the LAS. Power relationships in this context should be understood as describing the way in which actors are 'defined, associated and simultaneously obliged to remain faithful to their alliances' (Callon, 1986, pg. 224). Key to this process is a system of association in which actors are linked together through identities defined for them, which they may accept or decline.

\section{Creating the obligatory passage point}

When the LASCAD system collapsed in October 1992, the vision of total automation in call taking, vehicle tracking, resource allocation and mobilization for London's ambulance service was destroyed. The overarching viewpoint that the LAS needed to improve its performance remained intact, but the LASCAD system was no longer accepted as the mechanism (or OPP) for achieving that objective. Instead, deep divisions surfaced, both within and outside the LAS, on the appropriate mechanism.

\section{An attempt at problematization}


Publication of the Page report (February 1993) marked a new attempt at problematization. It identified roles and responsibilities for key actors. The senior management team should make a major investment 'in the workforce ... the fleet and the estate' (pg. 64). The IT director would 'have overall responsibility for all IT and communications planning and implementation' (pg. 63), including delivery of a new CAD system. The CAD system was defined as 'a complex multi-supplier, systems integration project' (pg. 63), which might take 'four years to develop and implement fully' (pg. 7). Staff should be consulted by management and see other evidence of management's 'commitment to, and appreciation of' them (pg. 9). In this way, the authors of the report may be seen to propose a system of alliances between human and non-human actors as the way to solving the problems of the LAS. This method of association proposed roles and responsibilities for key actors, in which their identities were defined in such a way as to be mutually reinforcing (Callon, 1986). This problematization was not only hypothetical but also incomplete. Some actors were not in post to accept the proposed identities; others who were in place might not accept them. Whilst a new CAD system was an actor in this context, it was not defined as an OPP. Instead, South Thames regional health authority, which commissioned the Page inquiry and became responsible for the LAS following the collapse of LASCAD, attempted to create an OPP in the many and diverse recommendations of the Page report. In this way, it sought to link its interests with the identities of key actors at the LAS. This analysis focuses on how that attempt was negotiated and translated over time, to create a stable network of interests with a new OPP.

\section{The responses of the management team}

The appointment by the regional health authority of the members of the new senior management team marked an initial stage in attributing the identities proposed in the Page report. This attribution of identities was only partly successful. The new managers slowed the pace of change, compared with the period 1990-1992. They accepted their identities in as much as they adopted a corporate plan and technology strategy that addressed organizational and technical infrastructures, but in the period to January 1995, service improvements on which funding for these plans was agreed, were not achieved. In particular, the IT director negotiated his identity as the procurer of a new CAD system, by focusing on improvements to technical infrastructure, which included rewiring the ambulance control room and replacing the emergency telephone system.

\section{The responses of staff}

Following the withdrawal of LASCAD, tensions existed among LAS staff about the feasibility of designing a CAD system for London. The fact that demand for ambulance services in London is demonstrably greater in scale than elsewhere in the UK caused many staff to believe 'that systems that might be adequate for other services would not be adequate for the LAS' (Page et al, 1993, pg. 20). The range of perspectives is reflected in the following comments:

there hasn't been a computer system built that could deal with our demand

there isn't one out there you can buy and I don't believe there's one that you can design that will be able to do it for us 
well, all right, maybe, maybe it could, but I'm going to reserve judgement

and then there were those who were 'more used to computers and more trusting that something would happen that was good for us' (LAS, 1998b).

In late 1992, staff in the control room were torn between a desire to 'get back to the way that we were [in other words, to manual operations]', and a recognition that this 'was by no means ideal' (LAS, 1998b). Reverting to full manual operations was seen as problematic because conveyor belts, used to transport call details from call takers to ambulance allocators (who assign vehicles to emergency calls), had been removed when LASCAD was implemented. So, in recognition of the overarching need to improve response times, control room staff made a short-lived attempt to continue using the call taking subsystem within LASCAD (LAS, 2000):

... that's the one bit of it that no one really wanted to let go of, because that was actually quite good, apart from the difficulties there were about the calls printing out .... we did try for a little while .... but there were too many risks involved in it, so we went completely back to handwriting calls, having to ferry them about the room because we weren't set up in a way that you could get them to [the allocators], we actually had to employ people to run the calls. (LAS, 1998b)

The decision to retain the call taking subsystem of LASCAD when the rest of the system was withdrawn, may be seen as the use by LAS management of an interessement device that proved unsuccessful. Had this subsystem proved more robust, it might have served to lock call takers into place in a new network (Callon, 1986) and thereby have facilitated enrolment of control room staff to a full CAD development. Instead a printing error was sufficient to break the fragile link joining this interest group into the network being built. When this attempt to move forward slowly was abandoned, the predominant identity of LAS staff became one of a desire to return to the state that existed in 1990, prior to the arrival of John Wilby as chief executive. This identity, whilst acknowledging the need to improve performance, was characterized by an attempt to achieve this using prevailing manual methods for the foreseeable future, supported by an increased number of staff. Thus the period to June 1994 was one of attempting to create a workable control room structure to support manual operations in an environment that was becoming increasingly unsuitable, not only because essential equipment had been removed, but also because noise and overcrowding intensified as staff numbers increased and call volumes rose. The futility of this approach, given the increasing pressures on the LAS, was brought sharply home to staff with the death of Nasima Begum, which forced a rejection of accepted methods of working and crystallized the need for change:

.... and just when we thought we were getting on top of things, we discovered we were not really; there are some pretty awful things possible that could go wrong, and did go wrong. (LAS, 1998b)

Here, the impact of the 'London effect', the belief that 'we're different, we're special' (LAS, 2000), is crucial. Comments in the earlier part of this section demonstrate both the rhetoric that LAS staff used to describe the 'London effect' and the ways in which they were unable to enact it, using either a completely manual system or an implementation, however selective, of LASCAD. This suggests that the task for LAS management of enrolling staff support for a new computer system required an approach that preserved the rhetoric whilst providing an alternative method of enactment. 


\section{The responses of the external lobby}

External bodies, including Government committees, community health councils, other ambulance services, the public and the media, were characterized by a range of identities reflecting perspectives critical of the LAS. These actors subscribed to the view that the LAS was not moving quickly enough to implement the recommendations in the Page report. Indeed, some were very sceptical that the LAS in its then current form was capable of implementing them (minutes of evidence to House of Commons Select Committee on Health, 1995). The external lobby voiced criticism in several ways, from drawing on public outrage following the death of Nasima Begum to call for better performance by the LAS, to suggesting that the service be broken up and amalgamated with other authorities (LAS, 1998a).

\section{A further problematization}

Wells' response to the conflicting interests examined in this section was to conclude that 'trust status would be a desirable objective for the London Ambulance Service' because it would 'strengthen and clarify the chain of management responsibility' to ensure that 'necessary improvements are implemented' and a 'high standard of service to the public' is provided (report foreword). This recommendation, proposed to take effect from April 1996, built on the rejection of existing methods of working following the death of Nasima Begum and facilitated the enrolment of conflicting groups within the service. Supporting recommendations strengthened and extended those in the Page inquiry report, including the need to develop a CAD system and to have a national review of ORCON standards. By focusing attention in the LAS on restoring public confidence, Wells neutralized criticism from external bodies and defined an OPP in trust status as the way to improving the performance of the LAS.

Wells used several sources of power to define both the OPP and the actors required traversing it. He used public outrage following the death of Nasima Begum to force LAS management and staff to speed up the pace of change and to persuade the Government to make sufficient funds available to enable this process. By couching his recommendations in terms of trust status, which few would argue was a desirable objective for the LAS, however unattainable they thought it might be, he was able to create the impression of unity of purpose in pursuit of a common beneficial goal. Finally, by publishing his findings in January, five months before the Select Committee, Wells was able to set the scene for change on a decisive but largely positive note, whilst indicating weaknesses in the LAS that the Select Committee would criticize.

In creating an OPP in trust status, Wells not only identified a crucial objective for the LAS, but, in the context of an established internal market within the UK NHS, arguably the only possible objective, if the LAS was to continue as an organizational entity in its own right. Thus Wells presented a problematization that was difficult to contradict, to the extent that the Select Committee also endorsed a trust status objective for the LAS, although they were concerned about whether this could be achieved by April 1996. Thus Wells, in his joint role as chairman of the public inquiry and chairman of the regional health authority, defined the problem in terms of a solution he appeared able to provide, and in this way he became, in Callon's (1986) terms, indispensable.

\section{Translating the actors}


In recommending that the LAS seek trust status, Wells linked the interests of the regional health authority to the identities he proposed for members of the LAS senior management team, and emphasized service improvements as a necessary condition to implement the proposed solution. Thus sustained progress towards implementation of a full CAD system during 1997, with implementation of a call taking system in September 1995, was a key part of the identity proposed for the IT director. Service improvements through new rostering arrangements, a redistribution of staff among ambulance stations and the introduction of standby arrangements (whereby crews wait in their ambulances for emergency calls) were a key part of the identities for other members of the senior management team. Each of these actors had some room for manoeuvre while their identities were stabilized.

Although Wells addressed issues on a number of fronts by defining an OPP in trust status, again I focus on technology issues. In that sense, the OPP was concerned with implementing a call taking system in September 1995, which would enable the necessary improvements in performance against ORCON standards to qualify for trust status in April 1996. In this way, although the objective of developing a full CAD system by 1997 was endorsed in the Wells report, implementing the full system was not part of the OPP, since the goal was to achieve trust status beforehand. Thus the Wells report did not address how, in light of continually rising call volumes, satisfactory performance as a trust would be maintained if a full CAD system was not installed during 1997. This analysis focuses on how the IT director defined, enrolled and mobilized support for technological developments, after negotiating his own identity, or more specifically, the definition of the technology he was required to implement.

\section{Negotiating the definition of technology}

During 1994 and 1995 the IT director, in collaboration with a few members of the senior management team, used the power of an ailing IT infrastructure to slow the pace of change to enable him to 'have something that I knew I could deliver' (LAS, 1998a). It was well-recognized among this group that this approach would 'be seen as stalling' (LAS, 1994b), yet Wells built on and formalized this approach, and then the Select Committee, in contrast to its comments on other management initiatives, reinforced this course of action. The IT director's strategy of portraying the LAS as 'an organization working hard to succeed and making significant progress' (LAS, 1998a) proved successful again on the issue of procurement of a new computer system. This time the Select Committee urged him to consider purchasing a packaged CAD system but did not insist, despite the successful experiences of other services and their insistence on many other things. So the IT director pursued an in-house development approach. Thus he employed existing infrastructural weaknesses as an interessement device to divert attention away from a full packaged CAD system towards a system with reduced scope (call taking only) built in-house on a sound IT infrastructure. In this way he negotiated his identity, whilst setting the scene for development of the CTAK system in which he became a key actor.

\section{The Golden Circle}

We turn now to how the IT director locked LAS staff into the network of interests around the CTAK system. Here the Golden Circle approach was employed. This approach involved managing change by partitioning activities, so as to isolate areas directly involved in a change from other influences both within and outside the LAS (LAS, 1994b, 1994c). The argument was that people outside the Circle were not affected by the change, hence should 
not interfere with it. The Circle was drawn around the 300 staff in the control room, who were defined as those with a legitimate interest in development of a call taking system. People outside the Golden Circle, including LAS ambulance crews, were not aware of the implementation date for the new system (LAS, 1998a). This approach identified the actors to be involved in the development and sought to disassociate them from those who might challenge the legitimacy of the project. It built on existing support within the control room for a call taking system and sought to persuade this group that such a system could be implemented successfully. Using rhetoric relating to how the LAS had failed before with both a bespoke development and a packaged solution, the IT director was able to introduce prototyping techniques (LAS, 1998a), which gave control room staff an identity, as an actively involved user group, within the development process. The IT director claimed that this approach was one that the LAS had not tried, and equally importantly, had not failed with, before. In calling what was happening the involvement of a user group, he had grounds for this claim, although prototyping was no more than a tactic employed in an overall bespoke development strategy.

Members of the user group were not aware of either the Golden Circle terminology or the related policy of partitioning until implementation of the call taking system in 1996 (LAS, 1998b, 2000). Yet the approach was laid out in the technology strategy written in late 1994 (LAS, 1994b). So control room staff were seduced into an alliance, the rules of engagement in which became apparent to them only over time. Nevertheless, these members of staff were aware that something was taking place in a shared space that was substantially different from the opposing regimes that characterized the LASCAD development; as when changes to the prototype were required:

We'd sit in our little huddles in the corner [outside the shared space] saying "what do you think we should do, ... what shall we say, and ... how will we handle this?", never quite sure what sort of reception you were gonna get. And we'd come away from those meetings [in the shared space] sometimes and say "hey ... we really can say what it is that we want-we can tell them we're gonna have to have it, and then we get it - this is good" (LAS, 1998b)

Responding to my comment that the Golden Circle excluded significant others, and especially the vehicle crews [a number of whom allegedly sabotaged the LASCAD implementation (minutes of evidence to House of Commons Select Committee on Health, 1995)], the IT director described the Golden Circle as follows:

It was, rather, a means of defence on one part and a means of captivating and
motivating the important and affected players on the other part. It was never
intended to disempower but rather empower those who felt so hopelessly ignored in
the CAD crash of before. It was about doing justice to those who paid a heavy price
during the CAD collapse and ensuring their views were dominant on the grounds
that others would be unaffected. It was about team spirit, togetherness, and a sense
of identity. It was often almost palpably tangible but sometimes gossamer like. It was
real, it was false, it was for use, it served no purpose, it hindered, it facilitated, it
empowered, it excluded, it included, it marginalised, it promoted strength, it
promoted willpower, but most of all, it worked!!!!! [exclamation marks in the
originall (I.AS. 1999)

Figure 1. The IT director's description of the Golden Circle. 
During enrolment, the IT director adopted an 'infiltration' approach with users (LAS, 1998a). Key individuals were identified who liaised between the technology department and the control room. These individuals were trusted by 'staff side' to protect its interests, whilst being considered supportive of the proposed changes by 'management side'. Deals made with both sides by these individuals were instrumental in enrolling and mobilizing support for technological change. The IT director described one such member of staff as:

a great lump of glue that brought all the interests together, because at that time [second half 1995] some people thought that they could talk to us and some people thought they couldn't, but they all thought they could talk to [member of staff].

The staff member, who described the role as cementing relationships, commented:

we made a pact with one another ... in trying to get the trust of the people in Control that we would not let anything happen that would be detrimental, so there were a lot of instances where we had to say "stop" ... we had to be sure that things that were allowed to go wrong last time couldn't go wrong this time ... we had to do a lot of work on helping people to believe that we wouldn't let us go down that route again, never again.

Within the Golden Circle, four different solutions were evaluated, prototypes of two of these were demonstrated to the user group, and then one was developed and built in joint consultation (LAS, 1998a). As the project progressed, different user requirements were addressed by inviting contributions from representatives of these interests (LAS, 1998b, 2000). These representatives spoke on behalf of the 300 staff in the control room and negotiated the final solution so that, ultimately, resources could be mobilized in readiness for implementation. Staff who were enthusiastic about computerization were seconded to the user group, and:

we made sure we threw in some sceptics as well, because if you could convince them, then that would do a lot of convincing of other people ... we could use them to spread the right sort of word ... they'd hear this person talking about such and such ... people would say "blimey, if he's saying it's all right, it must be OK ... because you can never please him”. (LAS, 1998b).

The Golden Circle approach and accompanying prototyping techniques resulted in an aligned network of interests around a call taking system called CTAK. Actors were translated towards this OPP through the use of power exercised in discourse. In this way, the approach illustrates the different aspects of the moments of translation: definition of actors; use of interessement devices, in the form of a partitioning rationale and prototype demonstrations to the user group, which locked actors into identities proposed for them and impeded other alliances; a negotiated process of enrolment in which deals, pacts and trials of strength accompanied the interessements and made them appear attractive; and designation of legitimate representatives for various interest groups during mobilization. In stabilizing the identities of control room staff, two considerations were crucial - their fear of failure, and their conflicting need to enhance selfesteem. In the first case, staff used the powerful image of a computer disaster on New Year's Eve to delay implementation of the new system from December 1995 to January 1996:

put yourself in the place of those people working on a strange system with the call rate rising as it does through December and reaching its peak on New Year's Eve ... why would we want to do this to them? (LAS, 1998b). 
In the second case, despite their view that 'we're different, we're special' (LAS, 2000), staff were conscious of how far behind other services the performance of the LAS had fallen:

... people were not out to sabotage trying to make it work ... people wanted to be not looked down upon ... not just by the public at large and the press particularly, but by other ambulance services. When we were at that stage [implementation], other ambulance services were moving on to their second computer system ... and there's us still fumbling around with pens and paper ... we didn't want to be the ones who are bad at doing things or so behind at doing things, so there was a lot of self-respect in there as well. (LAS, 1998b).

Whatever the rhetoric about the 'London effect', it seems clear that part of the identity of control room staff was that traversing the OPP would not only improve the performance of the LAS, but would also restore their sense of achievement and with it their self-esteem.

\section{DISCUSSION}

The above analysis of technological change emphasizes the use of power exercised in discourse to achieve translation. In this way, the IT director is seen to use persuasive rhetoric, concerning weaknesses in infrastructure and approaches to systems development, to enrol support from LAS staff, the Select Committee, and other external bodies, and to lock these potential allies into place. He translates the Select Committee's contention, that he purchase a packaged CAD system, into a bespoke development of a call taking system, and does so while the LAS is under considerable pressure to improve its performance in line with other services, many of which are using packaged CAD systems. Moreover, he persuades the user group of the merits of a bespoke development strategy, although this is a strategy that the LAS has tried and been unsuccessful with before, even if the introduction this time of prototyping techniques is a new tactic. In this analysis, then, the IT director emerges as a powerful actor who, despite sometimes protracted negotiations with others, manages to align them with his preferred strategy for information systems development.

Nevertheless, a relational concept of power informs the analysis. Action within the Golden Circle is seen as a negotiated process of systems development involving deals, pacts and trials of strength, which encourages more user input than had been the case during the LASCAD development. So, although some user requirements are challenged by IT staff, and other requests are keenly contested within the Circle, the sense of a joint if not unproblematic venture, rather than the pitched battle of the LASCAD project, prevails in the argument. Furthermore, members of the user group are seen to use persuasive rhetoric, both with their colleagues, to enrol the support of those sceptical about the project, and in their dealings with IT staff, to negotiate requirements and to delay implementation of the system until January 1996.

This analysis draws attention to the partitioning aspect of the Golden Circle, and to its covert nature during the early days of the CTAK project. Yet, the overall sense in the account is that, while power relations within the Golden Circle were asymmetrical, they were not essentially repressive (Foucault, 1980b). In making this claim, I need to address some key issues. Why was covert action thought necessary? How covert was such action, when uniform tells you so much about the wearer's role at the LAS? In this way, even without being aware of the contents of the technology strategy, was it not possible for members of the 
Golden Circle to establish by looking around at meetings which broad functions were represented? If members of the user group felt that others should be involved, did they not have a capacity to act, as when they argued that implementation of the CTAK system should be delayed until January 1996? Did those who were excluded have a capacity to intervene, if they felt a need to do so?

By way of addressing these issues I argue that, whether they called it the involvement of a user group or a means of managing change by partitioning activities, members of the Golden Circle were aware that the shared space was "made up" - that it was fabricated. Furthermore, whether they acknowledged it explicitly or implicitly, everyone knew who was included and who was not. In this way, all subscribed in some manner to the view that vehicle crews, and the various external bodies mentioned earlier, did not need to be involved directly in development of a call taking system to be used in the LAS control room. Nevertheless, members of the Circle were aware that the exclusion was not total, nor in some cases did they desire it so. In the day to day running of the LAS, staff in the control room must work with the vehicle crews, and therefore they considered the requirements of this relationship when developing the CTAK system. Moreover, they knew that the Select Committee and government ministers could have intervened in LAS affairs, if they felt that its approach to information systems implementation was not an appropriate way to spend public funds. Equally, inclusion in the Circle was not unproblematic. The approach encouraged more user input than had been the case previously at the LAS, nevertheless systems development efforts within the Circle were fragile events that needed constant attention to maintain the stability of the group.

In this way, the Golden Circle did not endow its creator, the IT director, with control, nor did it deprive the user group of autonomy. The IT director was, at times, overtaken by what he had created. When he says that the development process 'was very time consuming and wearing, to say the least' (Computer Bulletin, 1997, p. 23), he shows some of the surprise he felt. He did not expect a system that, in its initial implementation, comprised three data capture screens (one for each type of call), with related enquiry and printing facilities, to take nearly nine months to develop, but ' $[\mathrm{w}] \mathrm{e}$ had to move at a pace that everyone could cope with, no matter what their ability ... [which] meant explaining over and over what we were doing' (ibid). Members of the user group were also surprised by the extent of their autonomy, as in their comment that 'we really can say what it is that we want - we can tell them we're gonna have to have it, and then we get it - this is good' (in the analysis section of this paper).

The Golden Circle emerges as something that made action possible, despite certain fears experienced by its members: fear, for example, that sabotage might occur again, as alleged about the LASCAD implementation (minutes of evidence to House of Commons Select Committee on Health, 1995); fear, also, of another disaster, with all the media attention and public scrutiny that followed in the wake of LASCAD. Indeed, for many, a fear of experiencing fear again, the fear that gripped staff in the control room as they lost their sense of organization or structure when trying to use the LASCAD system (LAS, 2000-2001b).

Now, a paragraph I included in my analysis of the CTAK project starts to come alive. It is the IT director's response to reading an early draft of this paper, in which he felt I developed a rather limited view of the Golden Circle. In this rendering, we learn of the history of the Golden Circle, and get a sense of what it means to say that it was both exclusive and inclusive, both mysterious and rational, both constructed and real. I refer the reader to the IT 
director's words, in Figure 1, now that I have tried to give a greater sense of how I have come to understand them.

In this discussion, then, the Golden Circle emerges as a way of arguing and acting that made argument and action possible. Latour's (1999b) word for such an idea is a factish, although he seems resistant to the notion that social scientists can arrive at such a position from a Foucauldian informed discourse about power/knowledge relations. Nevertheless, with a little bit of prompting from Pandora's Hope, I seem to have managed that translation.

\section{Factishes, making-do and translation drift}

Factish is a neologism coined by Latour (1999b) to indicate a combination of fact and fetish. It is a type of action that does not force us to choose between real knowledge (facts) and powerful beliefs (fetishes), but rather to focus on ways of arguing and acting that are always fabricated. Such a view takes the position that there are neither amoral manipulators who take in naïve believers, nor apolitical moralists who argue for participation by all. Equally though, Latour would resist saying that there is a combination of the moralist and the politician in all of us, if this were to suggest that these elements can be retrieved independently, rather than being entangled, inseparable and shaped with same clay. The concept of a factish, then, is one example of Latour's (1999a) efforts to develop a vocabulary for actor-network theory that eschews distinctions such as power and knowledge, or politics and morality, that come to us ex ante loaded with meaning.

A factish is constructed, it is what holds people together, but this attachment does not decrease autonomy; rather it fosters it. In this way, we are always a little surprised, or overtaken, by what we do. That which acts through us is also surprised by what we do, 'by the chance to mutate, to change, and to bifurcate, the chance that I and the circumstances surrounding me offer to that which has been invited, recovered, welcomed' (Latour, 1999b, p. 281). A factish 'protects humans against inhumanity ... [it is] the thing that, when removed, turns them into monsters, animals, things' (p. 286).

When the Golden Circle is conceived as a factish, the rules of engagement in it are neither wholly mysterious nor entirely rational. Rather they are worked out as the project progresses, in a 'making-do, accomplished along with others in an event, with the specific opportunities provided by the circumstances' (Latour, 1999b, p. 288). The need for constant attention, with unforeseen consequences, to a fragile moral order and an unstable social one (ibid.) is emphasized. Action within the Golden Circle involves an ability to grasp opportunities provided in the moment. After translation, Latour (1999b) argues, a drift or slippage in the actors' original goals will be observed, in which they are surprised by what they have created.

A reading of the CTAK project in terms of making-do and translation drift suggests that, following the death of Nasima Begum, and arguably even before, the IT director was trying to find a way of arguing and acting that would make implementation of an information system possible at the LAS. He realized that '[u]sers' confidence was rock bottom, so [he] decided to start with some relatively safe but important [infrastructure] projects' (Computer Bulletin, 1997, p.23). In this environment, his realization that infrastructure projects were 'relatively safe' was arguably far more telling that his view that they are 'important'. Fear seems more significant in this move than the implementation of sound management practice. 
Similarly, the death itself may be seen as giving rise to a number of makings-do, that grasped the circumstances of the moment, in which previously accepted methods of working were rejected. In this way, the IT director's discourse with the user group about information systems development strategies and techniques, whether in the vocabulary of prototyping or "something the LAS has not used before", may be seen as one that helped to allay their mutual fears about sabotage and failure. Indeed, the CTAK system addressed a need - to provide more efficient and effective support for call taking - that was accepted at the LAS as far back as 1992. Thus the challenge for the IT director following the withdrawal of LASCAD was to find an approach to technology deployment that built on this need without jeopardizing the initiative by, at the same time, introducing some of the more controversial elements of a CAD system.

While much of the attention in this discussion has focused on discourses in which the IT director of the LAS was a key actor, similar concepts may be used to describe discourses in a broader community. In the context of the UK NHS, William Wells may be seen as someone who found a way of arguing and acting that made organizational change at the LAS possible. Following the death of Nasima Begum in June 1994, he argued that the service should aim to achieve NHS trust status. While undoubtedly some observers felt that the LAS could not achieve this objective, in the context of an established internal market within the UK NHS, there was an absence of voices raised in contradiction to Wells' proposal. In his joint role as chairman of the public inquiry into the death of Nasima Begum and as chairman of the regional health authority, Wells was able to support his proposal with additional Government funding worth $£ 15$ million. In this way, he grasped opportunities provided by the changing environment of the UK NHS, at a time when members of the LAS found their existing factish - of improved performance using manual methods of working - to be wanting.

\section{Postscript}

In the years that have elapsed since the LAS achieved trust status, its organizational change programme has continued alongside the need to respond to ever more demanding standards of performance. The basis on which ambulance services respond to emergency calls has altered. Now, services must prioritize the emergency calls they receive and respond to patients based on a clinical assessment of their need (Chapman, 1996). Performance targets for the number of responses to be achieved in 8 minutes and 14 minutes have also changed. A call prioritization system has been implemented at the LAS to support these arrangements (LAS, 2000-2001a). Limitations of the original CTAK system have been recognized and a number of enhancements to it have been made. Preparations for the millennium celebrations required significant effort, particularly since New Year's Eve is always the busiest night of the year at the LAS.

In all of this, implementation of the remaining four elements of a CAD system moved backstage (LAS, 2000). As of the end of 2001, a computerized mapping system provides a way of locating the position of ambulances, but no automated support is available for linking ambulances with the calls they are attending. In this way, the processes of allocating and mobilizing resources to incidents, managing ambulance resources, and the associated provision of management information, are still largely manual operations. The factishes, and hence the ways of making-do, have changed or metamorphosed. The complex interactions that account for this drift tell another story in the history of the LAS, one in which power relations and identity, fear and making-do, or however else we choose to argue, mixes up the 
politics and morality of technological change, again, in a very messy way. So we may conclude that while factishes provide us with ways of arguing and acting, they require constant attention to do so. Goals are interrupted, detours are taken, and shifts in meaning occur. Organizational change is precarious and unpredictable. Key actors can grasp specific opportunities, and accomplish things with others in an event, but since the event changes all of them, grasping further opportunities requires a subtle programme of action that is sensitive to a constantly changing collective (Latour, 1999b).

\section{CONCLUSIONS}

This paper is an account of events at the LAS over a four-year period, as it recovered from the collapse of LASCAD through a process of long-term, and ongoing, organizational change. This research draws on actor-network theory to focus on the implementation of a new computer system in 1996. The analysis is informed by the sociology of translation (Callon, 1986), and then arguments from that account are discussed in terms of concepts from Latour's (1999b) recent work. The analysis emphasizes the way various stratagems employed by key actors, including the use of persuasive rhetoric, helped to create and maintain network allegiances. The discussion interprets the political dimension of these actions, as an opportunistic effort to address a fear of information systems implementation within the organization. In this context, such fear existed following the implementation of the LASCAD system, in which it is alleged that 20 people died in 36 hours following protracted waits for an ambulance (Guardian, 1992; Independent, 1992, but see also Page et al, 1993 for a counter to these allegations). When the case is examined in terms of the concept of a factish, and a vocabulary of making-do (Latour, 1999b), the improvised and unanticipated nature of the change efforts is emphasized. Key actors are seen to grasp opportunities presented in the moment to engage support for information systems implementation at the LAS. The themes of fear and improvisation in organizations emerge from the analysis rather than being buried in the argument. These findings have implications for research and practice.

\section{Implications for practice}

Drawing on the Foucauldian arguments that inform the sociology of translation, the Golden Circle may be seen as a regime of truth (Foucault, 1980b), that is, as the way a given community makes the discourses it accepts function as true. In this view of activity, members of the community draw on knowledge that is both institutionally framed and locally informed, and enact it in a negotiated process in which some members obtain the right to speak for all. In the case of the LAS, various members of the Golden Circle drew on knowledge of best practice for information systems development and management, and on standards of good performance for ambulance services, and enacted this knowledge in a way that was sensitive to local conditions. In particular, they were sensitive to the history of information systems implementation at the LAS, and to issues of managing ambulance service operations in London. In this way, the Golden Circle provided a framework or model for information systems development and management, in which certain modes of arguing were accepted by its members, and were enacted by them in a way that addressed a dominant mood within the community. Following the collapse of LASCAD, the dominant mood was fear, in particular fear of failure and fear of sabotage.

Drawing on Latour's (1999b) arguments about the nature of a factish, the Golden Circle was a way of arguing and acting that made implementation and use of an information system 
possible. It protected its members, as well as making it possible for them to accomplish things together. Here, I emphasize how mood, as an attunement with the situation and a medium within which activities take place (Ciborra, 2001) influenced the way that actors performed. Key actors within the user group approached this period of information systems development in an anxious mood, fuelled by their experiences during the LASCAD project. The IT director was anxious too, given the stakes involved, but he sought to combat this mood, to drive it away (Ciborra, 2001, citing Heidegger, 1995), by grasping opportunities as they arose, and by presenting what he was doing in a persuasive way to internal and external audiences.

In the mood in which they approached systems development, members of the Golden Circle sought to provide automated support for a limited number of control room activities, which in turn limited the number of people who were thought to be directly involved. The rules of engagement in the Golden Circle were negotiated as the project progressed, as it became clearer who needed to be involved and who did not. In seeking to prevent interference by those who were not seen as directly involved, the Golden Circle became a protection against fear, but by attending to their structure, members of the Circle found that their capacity to act increased (Weick, 1993). In this way, systems development activity within the Golden Circle was action in which there was time available, there were resources at hand, and there was a solution to the problem that had to be addressed. In other words, members of the Circle acted in a way that seems to be influenced by most of the attributes that fear does not have - they improvised. The CTAK system emerges from the process as something built by the group in interaction, rather than being, in a more traditional view of information systems development, the product of a structured sequence of activities, such as feasibility, requirements analysis, system design and development, implementation.

Writers on improvisation argue that what takes place becomes 'visible only after the fact' (Weick, 1993, p. 348), so that action that 'looks extemporaneous ... [then] turns out to be highly competent behaviour' (Ciborra, 1999, p 136-7). In this way, it may be argued that what took place within the Golden Circle was broadly in line with a prototyping approach to information systems development - an approach considered by many to be a highly competent way to manage the development process. However, the IT director (Computer Bulletin, p. 23) presents what occurred as the implementation of a decision taken ex ante ('we chose prototyping'), whereas the argument of the last section is that such a rationalization only became possible post facto. The latter argument explains why members of the user group felt uncertain about how to handle requests for changes to the prototype, and concerned about how these requests would be received by IT staff, while at the same time they felt able to make such requests. If a decision to adopt prototyping had been agreed in advance, it seems unlikely that key members of the user group would have experienced the combination of uncertainty and empowerment that took place within the Golden Circle. Rather the degrees of both experiences would probably have been reduced, since a greater degree of certainty about how to act during prototyping might have suggested that a greater licence to act should be taken for granted.

This research, then, suggests that frameworks or models for information systems development and management should address emotional as well as cognitive aspects, and also the interrelationship between these two dimensions. In this way, they need to attend to the moods in which actors approach the task of systems development. Furthermore, they should address the way that, in responding to a mood, actors may engage in various degrees 
of improvised activity. Finally, they should not underestimate the attention that is needed to modes of arguing and acting to create and maintain the stability of a group involved in a systems development effort. Existing frameworks, whether based on a lifecycle or an evolutionary model, and whether informed by an engineering approach or a socio-technical one, neglect or underplay one or more of these considerations. Further research might explore the relationship between moods, modes of arguing and acting, and models for information systems development and management in different settings. Such research might draw on the existing body of literature in organizational theory on emotion in the workplace, for example Fineman's (2000) edited volume, which provides an overview of the main areas of concern and a collection of papers exploring key themes. These ideas would complement existing perspectives in information systems research which, in general, view systems development as a cognitive process, and more specifically, fail to exploit the works of Foucault for emotionality.

\section{Implications for teaching and research}

The information systems development activity described in this case, in particular the actions of the IT director during the CTAK project, may be seen as a very effective improvised performance. While such an account of making-do is considered highly reputable in certain branches of research, the normative literature read by managers shows less tolerance for a rendering of improvised responses to specific circumstances. Rather, much of that literature, and trade journals in particular, seek to explain what takes place in terms of adherence to best practice, underplaying the ad hoc element of action, as in an account of the CTAK project published in Computer Bulletin (1997). That account is 'based partly on recent presentations by [the IT director of the LAS] to the BCS [British Computer Society] London Medical and Project Management specialist groups' (p. 24), and the words of the IT director are cited throughout. Paradoxically, then, even when practitioners give a very competent improvised performance, they are unlikely to acknowledge it as such.

The notion of improvisation in organizations has implications for how we teach, how we do research, and how we write about what we do. Many managers are educated via professional courses to understand their actions in terms of normative discourses, so it is hardly surprising that they present rationalistic accounts of their achievements, even when their experience suggests otherwise. It was only when I challenged the IT director - when I influenced his mood - by presenting what he considered to be a limited view of the Golden Circle, that I prompted him to give the much richer description of it discussed earlier. This suggests a need to give more attention to the improvisation literature in management education. While improvisation, never mind the moods to which it might be a response, remains largely a concept that people in organizations use to describe jazz or theatre, but not their own work, we may be neglecting a way of arguing and acting that could enrich both research and practice. Furthermore, if all activity involves some degree of improvisation (Weick, 1998), then writing is an improvised performance. With this argument in mind, academic journal editors and reviewers might act so as to create possibilities for a greater number of papers that adopt a tentative and open-ended style - a style that seems to characterize improvised activity, and with which I bring this paper to a close.

Thus, I do not claim that an account of the CTAK project in terms of factishes and making-do (Latour, 1999b) either overcomes or bypasses an account informed by a sociology of translation (Callon, 1986) and a power/knowledge relationship (Foucault, 1980a). Rather, 
these accounts seem to complement one another. In this way, I have translated the ideas of two major proponents of actor-network theory to arrive at fear and improvisation - or moods, modes of arguing and acting, and a tentative model for information systems development and management - which may be a different place altogether. Latour's (1999b) nonmodern way of arguing invited me to improvise, so I took the opportunity 'to mutate, to change, and to bifurcate' (p. 281) as well as I am able to do, with what I had to hand, and in the mood in which Pandora's Hope left me. It is for readers to decide how effective I have been.

\section{Acknowledgements}

I would like to thank several people for their help and support during the course of this study. They include Ray Paul for encouraging me to write, Chrisanthi Avgerou and Steve Smithson for their ongoing support, the associate editor and two anonymous reviewers of this journal for their helpful comments on my work, and numerous members of staff at the London Ambulance Service.

\section{REFERENCES}

BEYNON-DAVIES, P. (1995). Information systems 'failure': The case of the London Ambulance Service's Computer Aided Despatch project. European Journal of Information Systems, 4, 171-184.

CALLON, M. (1986). Some elements of a sociology of translation: Domestication of the scallops and the fishermen of St. Brieuc Bay. In Power, Action and Belief: A New Sociology of Knowledge? (LAW, J., Ed.), Routledge and Kegan Paul, London.

CALLON, M. (1991). Techno-economic networks and irreversibility. In A Sociology of Monsters: Essays on Power, Technology and Domination (LAW, J., Ed.), Routledge, London.

CALLON, M. and LATOUR, B. (1992). Don't throw the baby out with the Bath School! A reply to Collins and Yearley. In Science as Practice and Culture (PICKERING, A., Ed.), University of Chicago Press, Chicago.

CHAPMAN, R. (1996). Review of Ambulance Performance Standards, Department of Health, July.

CIBORRA, C. (1999). A theory of information systems based on improvisation. In Rethinking Management Information Systems (CURRIE, W. and GALLIERS, R., Eds.), Oxford University Press, Oxford.

CIBORRA, C. (2001). In the mood for knowledge: A new study of improvisation. Paper presented to the Social Study of Information Technology Workshop, London School of Economics, 19-20 March.

COLLINS, H. and YEARLEY, S. (1992). Epistemological chicken. In Science as Practice and Culture (PICKERING, A., Ed.), University of Chicago Press, Chicago.

COMPUTER BULLETIN (1997). 999 Rescue, October. 
FINANCIAL TIMES (1993). When failure followed failure, 26 February, 10.

FINEMAN, S. (Ed.) (2000). Emotion in Organizations. Sage, London.

FOUCAULT, M. (1980a). Power/Knowledge: Selected Interviews and Other Writings 19721977 (GORDON, C., Ed.), Harvester Press, Brighton, Sussex.

FOUCAULT, M. (1980b). Truth and power. In Power/Knowledge: Selected Interviews and Other Writings 1972-1977 (GORDON, C., Ed.), Harvester Press, Brighton, Sussex.

GIDDENS, A. (1979). Central Problems in Social Theory. MacMillan, London.

GIDDENS, A. (1984). The Constitution of Society. Polity Press, Cambridge.

GUARDIAN (1992). Ambulance chief resigns, 29 October.

HARBERS, H. (1995). Book review: 'We Have Never Been Modern' by Bruno Latour. Science, Technology and Human Values, 20(2), 270-275.

HEIDEGGER, M. (1995). The Basic Problems of Phenomenology. Indiana University Press, Indiana.

HOUGHAM, M. (1996). London Ambulance Service computer-aided despatch system. International Journal of Project Management, 14(2), 103-110.

HOUSE OF COMMONS SELECT COMMITTEE ON HEALTH (1995). Second Report on London's Ambulance Service, June.

HOUSE OF COMMONS SELECT COMMITTEE ON HEALTH (1996). First Report on the London Ambulance Service: Comments on Recent Performance, December.

HULL, R. (1999). Actor network and conduct: the discipline and practices of knowledge management. Organization, 6(3), 405-428.

INDEPENDENT (1992). Software failure may be behind ambulance crisis, 30 October.

INTRONA, L. (1997). Management, Information and Power. MacMillan Press, London.

KNIGHTS, D. and MURRAY, F. (1994). Managers Divided: Organisation Politics and Information Technology Management. Wiley, Chichester.

KNIGHTS D., MURRAY, F. and WILLMOTT, H. (1997). Networking as knowledge work: a study of strategic inter-organizational development in the financial services industry. In Information Technology and Organizations (BLOOMFIELD, B., COOMBS, R., KNIGHTS, D. and LITTLER, D., Eds.), Oxford University Press, Oxford.

LATOUR, B. (1987). Science in Action. Open University Press, Milton Keynes. 
LATOUR, B. (1991). Technology is society made durable. In A Sociology of Monsters: Essays on Power, Technology and Domination (LAW, J., Ed.), Routledge, London.

LATOUR, B. (1996). Aramis, or the Love of Technology. Harvard University Press, Massachusetts.

LATOUR, B. (1999a). On recalling ANT. In Actor Network Theory and After (LAW, J. and HASSARD, J., Eds.), Blackwell, Oxford.

LATOUR, B. (1999b). Pandora's Hope. Harvard University Press, Massachusetts.

LAW, J. (1986). Editor's introduction: power/knowledge and the dissolution of the sociology of knowledge. In Power, Action and Belief: A New Sociology of Knowledge? (LAW, J., Ed.), Routledge and Kegan Paul, London.

LAW, J. (1991). Introduction: monsters, machines and sociotechnical relations. In A Sociology of Monsters: Essays on Power, Technology and Domination (LAW, J., Ed.), Routledge and Kegan Paul, London.

LAW, J. (1999). After ANT: Complexity, naming and topology. In Actor Network Theory and After (LAW, J. and HASSARD, J., Eds.), Blackwell, Oxford.

LAW, J. and CALLON, M. (1992). The life and death of an aircraft: a network analysis of technical change. In Shaping Technology/Building Society: Studies in Sociotechnical Change (BIJKER, W. and LAW, J., Eds.), MIT Press, Massachusetts.

LONDON AMBULANCE SERVICE (LAS) (1993). Corporate Plan 1993/4-96.

LONDON AMBULANCE SERVICE (LAS) (1994a). Corporate Plan 1994/5.

LONDON AMBULANCE SERVICE (LAS) (1994b). Technology Strategy, September.

LONDON AMBULANCE SERVICE (LAS) (1994c). The Golden Circle: Rules of Engagement.

LONDON AMBULANCE SERVICE (LAS) (1995). Report to South Thames Regional Health Authority on LAS Performance, June.

LONDON AMBULANCE SERVICE (LAS) (1998a). Interviews with Director of Technology, Estates and Fleet, April, June and July.

LONDON AMBULANCE SERVICE (LAS) (1998b). Interview with member of the Central Ambulance Control management team, July.

LONDON AMBULANCE SERVICE (LAS) (1999). Personal communication from Director of Technology, Estates and Fleet, January.

LONDON AMBULANCE SERVICE (LAS) (2000). Meetings with front line staff from Central Ambulance Control, April-December. 
LONDON AMBULANCE SERVICE (LAS) (2000-2001a). Project meetings relating to implementation of a computerized priority despatch system at the London Ambulance Service, August 2000 - January 2001.

LONDON AMBULANCE SERVICE (LAS) (2000-2001b). Interviews with former front line staff, now members of front line support functions, December 2000-February 2001.

LONDON AMBULANCE SERVICE WEB SITE. https://www.londonambulance.nhs.uk. Various entries, accessed 7 March 2002.

PAGE, D., WILLIAMS, P. and BOYD, D. (1993). Report of the Inquiry into the London Ambulance Service. South West Thames Regional Health Authority, 25 February.

PETTIGREW, A. (1987). Context and action in the transformation of the firm. Journal of Management, 24(6), 649-670.

PETTIGREW, A. (1990). Longitudinal field research on change: Theory and practice. Organization Science, 1(3), 267-291.

REED, M. (1997). In praise of duality and dualism: Rethinking agency and structure in organizational analysis. Organization Studies, 18(1), 21-42.

TIMES (1997). Life-savers taste success after the years of tears, 21 May.

WALSHAM, G. (1993). Interpreting Information Systems in Organizations. Wiley, Chichester.

WALSHAM, G. (1997). Actor-network theory and IS research: Current status and future prospects. In Proceedings of the IFIP WG8.2 Working Conference on Information Systems and Qualitative Research (LEE, A., LIEBENAU, J. and DeGROSS, J., Eds.), Chapman and Hall, London.

WALSHAM, G. (2001). Making a World of Difference: IT in a Global Context. Wiley, Chichester.

WASTELL, D. and NEWMAN, M. (1996). Information systems design, stress and organisational change in the ambulance services: A tale of two cities. Accounting, Management and Information Technologies, 6(4), 283-300.

WEICK, K. (1993). The collapse of sensemaking in organizations: The Mann Gulch disaster. Administrative Science Quarterly, 38(4), 628-652.

WEICK, K. (1998). Improvisation as a mindset for organizational analysis. Organization Science, 9(5), 543-555.

WELLS, W. (1995). Report on the London Ambulance Service following the death of Nasima Begum. South Thames Regional Health Authority, January.

WINNER, L. (1993). Upon opening the black box and finding it empty: social constructivism and the philosophy of technology. Science, Technology and Human Values, 18(3), 362-378. 
